\title{
Article
}

\section{Hip kinematics and kinetics in total hip replacement patients stratified by age and functional capacity}

\author{
Lunn, D.E, Chapman, G.J and Redmond, A.C
}

Available at http://clok.uclan.ac.uk/28262/

Lunn, D.E, Chapman, G.J ORCID: 0000-0003-3983-6641 and Redmond, A.C (2019) Hip kinematics and kinetics in total hip replacement patients stratified by age and functional capacity. Journal of Biomechanics, 87 . pp. 19-27. ISSN $0021-9290$

It is advisable to refer to the publisher's version if you intend to cite from the work. http://dx.doi.org/10.1016/j.jbiomech.2019.02.002

For more information about UCLan's research in this area go to http://www.uclan.ac.uk/researchgroups/ and search for <name of research Group>.

For information about Research generally at UCLan please go to http://www.uclan.ac.uk/research/

All outputs in CLoK are protected by Intellectual Property Rights law, including Copyright law. Copyright, IPR and Moral Rights for the works on this site are retained by the individual authors and/or other copyright owners. Terms and conditions for use of this material are defined in the policies page.

\section{CLoK}

Central Lancashire online Knowledge www.clok.uclan.ac.uk

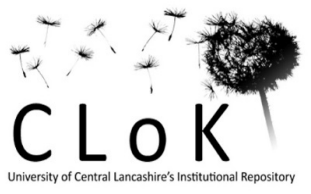


Hip kinematics and kinetics in total hip replacement patients stratified by age and functional capacity.

David E Lunn ${ }^{1,2}$, Graham J Chapman ${ }^{1,2,3^{*}}$, Anthony C. Redmond ${ }^{1,2,4}$

${ }^{1}$ Institute for Rheumatic and Musculoskeletal Medicine, University of Leeds, Leeds, UK

${ }^{2}$ NIHR Leeds Biomedical Research Centre, Leeds, UK

${ }^{3}$ Arthritis Research UK Experimental Arthritis Centre, Leeds, UK

${ }^{4}$ Arthritis Research UK Centre for Sports, Exercise and Osteoarthritis, Nottingham, Oxford, Loughborough, Leeds, UK.

Email addresses:

Dr David E. Lunn- d.lunn@leeds.ac.uk

Professor Anthony C. Redmond- a.redmond@leeds.ac.uk

* Corresponding author:

Dr Graham J Chapman PhD

Leeds Institute of Rheumatic and Musculoskeletal Medicine, University of Leeds and NIHR Leeds Biomedical Research Centre

2nd Floor, Chapel Allerton Hospital

Harehills Lane

Leeds, LS7 4SA

Tel: 01133924926

Fax: 01133924991

g.j.chapman@leeds.ac.uk

Word Count: 3499 


\section{Abstract}

To examine functional differences in total hip replacement patients (THR) when stratified either by age or by functional ability as defined by self-selected walking speed. THR patients and a control group underwent three-dimensional motion analysis under self-selected normal and fast walking conditions. Patients were stratified into five age groups for comparison with existing literature. The THR cohort was also stratified into three functional groups determined by their self-selected gait speed (low function <1S.D of total cohort's mean walking speed; high function >1S.D; normal function within 1S.D). Hip kinematics, ground reaction forces, joint moments and joint powers in all three planes (x-yz) were analysed. 137 THR and 27 healthy control patients participated. When stratified by age, during normal walking the youngest two age groups walked quicker than the oldest two groups $(p<0.0001)$ but between-group differences were not consistent across age strata. The differences were diminished under the fast walking condition. When stratified by function, under normal walking conditions, the low function and normal function THR groups had a reduced extension angle (mean $=1.75^{\circ}, \mathrm{SD}= \pm 7.75,1.26^{\circ} \pm 7.42$, respectively) compared to the control group $\left(-6.07^{\circ} \pm 6.43\right.$; $p<0.0001)$. The low function group had a reduced sagittal plane hip power $(0.75 \mathrm{watts} / \mathrm{kg} \pm 0.24)$, reduced flexor $(0.60 \mathrm{Nm} / \mathrm{kg} \pm 0.85)$ and extensor moment $(0.51 \mathrm{Nm} / \mathrm{kg} \pm 0.17)$ compared to controls $(p<0.0001)$. These differences persisted under the fast walking condition. There were systematic differences between patients when stratified by function, in both walking conditions. Age related differences were less systematic. Stratifying by biomechanical factors such as gait speed, rather than age, might be more robust for investigating functional differences.

Keywords: Total hip replacement, Gait, Stratification, Biomechanics, Functional outcomes 


\section{Introduction}

Total hip replacement (THR) is widely accepted as one of the most successful orthopaedic surgeries (Learmonth et al., 2007), despite small but persisting functional deficits in post-THR patients compared to healthy counterparts (Beaulieu et al., 2010; Colgan et al.; Ewen et al., 2012; Foucher et al., 2007; Kolk et al., 2014; Perron et al., 2000).

THR patients are often viewed as a homogenous group and few studies have explored how patient characteristics such as age can differentially influence function post-THR, potentially due to the relatively small sample sizes employed. For example, in a recent systematic review, only four gait studies out of 74 employed a sample size greater than 45 THR patients(Bahl et al., 2018). In a larger sample of patients from multiple retrospective studies, results demonstrated younger THR patients are more likely to recover function to a clinically meaningful level compared to older patients (Foucher, 2016), potentially due to older patients' limited hip sagittal ROM and hip power generation post-operatively. When stratifying gait function by age in a large cohort $(n=134)$ of THR patients, gait kinematics and kinetics are not influenced by age, except a reduced ROM exhibited in the 80 years and over age group (Bennett et al., 2008; Bennett et al., 2017), a finding consistently observed in healthy control patients of a similar age (Nigg et al., 1994). These findings suggest minimal gait differences are attributable to the replacement and that THR patients are relatively homogeneous and chronological age may not be a particularly sensitive indicator of function. A widely used alternative measure of overall functional ability is self-selected walking speed (Middleton et al., 2015; Studenski et al., 2011). Despite the expected negative overall association between age and gait speed (Bohannon and Williams Andrews, 2011), chronological age only explains 30\% of the variance in gait speed(Alcock et al., 2013), suggesting gait speed might be differential indicator of function compared to age. This has been explored in THR studies using self-reported functional ability (Bolink et al., 2016) and measured objectively by O'Connor et al (2018) who reported on a small sample of 22 THR cases, noting that hip contact forces are different between THR groups when stratified by walking speed. There is 
increasing evidence to suggest that patient demographic characteristics, such as age and gender are important factors in the overall survivorship of hip implants (Bayliss et al., 2017; Towle and Monnot, 2016) and so there is a need to understand the interplay between a range of demographic and functional patient characteristics on post-operative joint function. The purpose of the current paper was to build on the observation of differences between THR patient groups identified by O'Connor et al (2018) and to stratify our large THR sample by walking speed to explore whether gait speed may be a more appropriate measure of functionality than age.

The primary aim of this study was to examine the functional differences in a large THR cohort when stratified by age, for comparison with the existing literature, and to determine how stratifying by functional ability subsequently effects the interpretation of joint kinematics and kinetics after THR. Furthermore, while the majority of gait studies measure patients' function at a single self-selected walking speed(Kolk et al., 2014), in the real-world, patients walk at different speeds depending on environmental conditions and behavioural demands. This study also explored the effect of walking at a higher demand fast-pace to provide a more comprehensive model of patients function on a day-today basis, and potentially to explore greater differentiation between strata(Lamontagne et al., 2011).

\section{Method}

\section{Patients}

137 THR patients were recruited through a clinical database of surgical cases, and 27 healthy control patients were recruited from local community groups. THR group inclusion criteria were; between 15 years THR post-surgery, aged 18 years and older, no lower limb joint replaced except hip joint(s), fully pain free and not suffering from any other orthopaedic or neurological problem which may compromise gait. The same inclusion criteria were applied to the healthy control group except no participants had a joint replacement. Ethical approval was obtained via the UK national NHS ethics (IRAS) system and all participants provided informed, written consent. 


\section{Data Capture}

Each patient undertook one session of gait analysis under two conditions, i) a self-selected walking speed (hereafter referred to as normal walk) and ii) fast walk, where patients were instructed to walk "as fast as possible without running" along a 10m walkway. Lower limb kinematics and kinetics were collected using a ten camera Vicon system (Vicon MX, Oxford Metrics, UK) sampling at $100 \mathrm{~Hz}$, integrated with two force plates (AMTI, Watertown, MA, USA) capturing at $1000 \mathrm{~Hz}$. For the THR group, the operated limb (or most recently operated limb, in bilateral cases) was used for analysis and the dominant limb was selected for the control group, as chosen by the participant. All participants had a familiarisation period prior to completing 3-5 successful trials of each walking condition. A successful trial was defined as a clean foot strike within the boundary of the force plate. The CAST marker set was used to track lower limb segments kinematics in six degrees of freedom, with four non-orthogonal marker clusters positioned over the lateral thighs, lateral shanks and sacrum(Benedetti et al., 1998; Cappozzo et al., 1995). Each foot was modelled as a rigid, single segment, with six retroflective markers positioned on the first, second and fifth metatarsophalangeal joints as well as the malleoli and calcanei. Participants wore tight fitting shorts and vest onto which reflective markers were affixed at bony anatomical landmarks using double-sided tape to determine anatomical joint centres. Ankle and knee joint centres were defined as midpoints of the malleoli and femoral epicondyles, respectively. A regression model based on the position of the anterior and posterior superior iliac spine was used to find the hip joint centre(Bell et al., 1987). Before walking trials commenced, a static trial was collected to determine the position of the marker clusters with respect to lower limb joint locations.

\section{Data Analysis}


All markers were labelled and gap-filled using the spline fill function in Vicon Nexus 2.5 (Vicon MX, Oxford Metrics, UK). Labelled marker coordinates and kinetic data were exported to Visual 3D (Cmotion, USA) for further analysis. Kinematic data and ground reaction force (GRF) data were filtered using a low-pass Butterworth filter $(6 \mathrm{~Hz}$ and $25 \mathrm{~Hz}$, respectively). Heel strike and toe-off were determined using thresholds ( $>20 \mathrm{~N}$ and $<20 \mathrm{~N}$, respectively) from the GRF. Gait speed and averaged peak hip kinematic, normalised to $100 \%$ of the gait cycle and kinetic values, normalised to $100 \%$ of stance phase, are presented in the sagittal $(x)$, frontal $(y)$ and transverse $(z)$ planes. GRF, internal hip joint moments and powers are reported for stance phase. See supplementary data for averaged kinematic and kinetic waveforms. Due to the large number of variables analysed, only significant findings are reported here.

\section{Patient Stratification}

Patients were initially stratified by age into five groups; 1) age 54 to 64 years, 2) 65 to 69 years, 3) 70 to 74 years, 4) 75 to 79 and 5) 80 years and over, to compare to previous literature(Bennett et al., 2008; Bennett et al., 2017).

In the main analysis, patients were stratified into three functional strata determined by their selfselected gait speed, during normal walking. The mean and standard deviations (SD) of the gait speeds for the whole cohort were determined and those patients with a gait speed falling within 1SD of the mean were defined as normally functioning (NF). Patients with a gait speed greater than 1SD above the mean or 1SD below the mean were defined as high functioning (HF) or low functioning (LF), respectively. 


\section{Statistical analysis}

Between-strata differences were tested using a one-way ANOVA, and Levene's test performed to test for the equality of variance. If homogeneity of variance was identified, Tukey's post-hoc test was performed, if not, Tamhane's post-hoc test was used. Statistical analysis was performed using SPSS (Version 21, Chicago, IL) with the significance level set at $p<0.05$. Main effect $p$-values calculated and given this was an exploratory study, no correction applied for the multiple testing, to highlight variables of potential interest rather than to support wider inference.

\section{Results}

\section{Age Strata - Demographics and Walking Speed}

All 137 patients completed the normal walking condition and 120 completed the fast walking condition. Table 1 shows each age strata demographics and for brevity, age strata will be referred to by group number designated in Table 1. During normal walking, there was a consistent trend towards decreasing gait speed with increasing age and the youngest two groups (Group 1 and 2) walked significantly faster than the older two groups (Group 4 and $5, p<0.0001$ ). During fast walking, there was no consistent trend.

\section{- Insert Table 1 here -}

\section{Age Strata- Normal Walk}

Table 2 and 3 presents peak hip joint kinematics and kinetic data for each age strata under both normal and fast walking conditions, respectively. 


\section{Kinematics}

All age strata demonstrated reduced sagittal ROM compared to the control group $(p<0.0001)$, with the three oldest groups (Group 3, 4 and 5) showing a reduced peak extension angle $(p<0.0001)$ (Table 2). Compared to the control group, maximum adduction angle in Group 2 was significantly lower $(p=0.045)$ and Group 4 exhibited a significantly reduced frontal ROM ( $p=0.009)$.

\section{- Insert Table 2 here}

Moments

Groups 2 and 4 exhibited significantly reduced peak abductor moments compared to the control group, in addition, Group 4 exhibited significantly lower abductor moments compared to Group 1 $(p=0.002)$. Group 4 demonstrated significantly reduced peak flexor moments compared to the Group 2 and control group $(p=0.016)$.

Powers

All THR patients exhibited significantly reduced peak sagittal hip power generation compared to the control group $(p<0.0001)$, in addition to the two oldest groups demonstrating significantly reduced peak sagittal hip power absorption $(p<0.0001)$. Frontal plane power generation and absorption, were significantly higher in the youngest group $(p<0.0001)$ compared to Group 4.

\section{Age Strata - Fast Walk}




\section{Kinematics}

The three oldest THR age groups exhibited significantly reduced peak hip extension compared to the controls ( $p=0.002$ ). Sagittal ROM was significantly reduced in Groups 2,4 and 5 compared to the control group ( $p=0.001)$. Group 4 demonstrated significantly reduced frontal plane ROM compared to the control group $(p=0.016)$.

\section{- Insert Table 3 here -}

\section{Moments}

Group 1 exhibited a significantly higher peak adductor moments compared to Group 4 and the control group ( $p=0.017)$. Group 4 displayed a significantly reduced abductor moment compared to Group 1 and the control group.

Powers

Compared to the control group, Groups 2 and 5 exhibited significantly reduced sagittal hip power generation $(p=0.016)$ and the youngest patient group demonstrated higher frontal peak power absorption compared to Group $4(p=0.022)$.

\section{Functional Strata - Demographics and Walking Speed}

The mean self-selected walking speed in the full THR cohort was $1.1 \mathrm{~m} \cdot \mathrm{s}^{1}$, with the LF $(n=19)$ and HF group ( $n=19)$ comprising of all cases with a gait speed $<0.93 \mathrm{~m} \cdot \mathrm{s}^{1}(\leq 1 \mathrm{SD})$ and $\geq 1.26 \mathrm{~ms}^{-1}(\geq 1 \mathrm{SD})$, respectively. The NF group ( $n=99$ ) were all patients who fell within 1 SD range of the mean. Table 4 
shows the demographics for each functional stratum. During walking and fast walking, the LF group and HF group walked significantly slower and quicker, respectively, than all other groups $(p<0.0001$, see Table 4).

\section{-Insert Table 4 here-}

\section{Functional Strata - Normal Walk}

Table 5 and 6 presents peak hip joint kinematics and kinetic data for each functional stratum under both normal and fast walking conditions, respectively

Hip Kinematics

Peak extension were significantly reduced in the LF and NF groups compared to the control group $(p<0.0001)$. All post-THR groups demonstrated significantly reduced sagittal ROM compared to the controls, and the LF group demonstrated significantly reduced hip ROM compared to NF and HF group $(p<0.0001$, Figure 1$)$. The LF group displayed a significantly lower frontal plane ROM compared to the control group $(p=0.006)$.

\section{- Insert Table 5 and Figure 1 here -}

\section{Hip Moments}

The LF group demonstrated a significantly reduced flexor and extensor moment compared to all other groups ( $p<0.0001$, Figure 1). Conversely, the HF group exhibited an increased peak extensor moment compared to the NF group $(p<0.0001)$. The LF group also displayed significantly reduced abductor moment compared to the control and HF group $(p=0.006)$. 
Hip Powers

The LF group demonstrated significantly reduced sagittal plane hip power generation compared to all other groups $(p<0.0001)$. Additionally, the NF group demonstrated significantly reduced sagittal plane hip power generation compared to the HF and control group $(p<0.0001)$. The LF and NF groups exhibited significantly reduced sagittal plane hip absorption power compared to the HF and control group $(p<0.0001)$.

\section{Functional Strata- Fast Walk}

\section{Kinematics}

Peak extension angle was significantly less in the NF group compared to the control group $(p=0.005)$. Compared to the control group, sagittal plane ROM in the LF and NF group was significantly reduced $(p<0.0001$, Figure 2). NF group peak adduction angle $(p=0.046)$ and LF group frontal plane ROM was significantly reduced $(p=0.012)$ compared to controls.

\section{- Insert Table 6 and Figure 2 here -}

\section{Hip Moments}

Peak flexor moments in the LF group were significantly reduced compared to all other groups and the NF group was significantly reduced compared to the HF group ( $p<0.0001$, Figure 2$)$. The LF group demonstrated significantly lower abductor moments compared to the control group $(p=0.028)$.

Hip Power 
Sagittal plane hip power generation and absorption was significantly lower in the LF group compared to the HF and control group $(p<0.0001)$. The NF group exhibited significantly lower sagittal power generation $(p<0.0001)$ compared to the $\mathrm{HF}$ and control groups. Additionally, the NF group was significantly different to the HF group for hip sagittal power absorption $(p<0.0001)$.

\section{Discussion}

This study sought to identify how stratifying patients either by age, or gait speed as a measure of function, can influence post-THR hip function, under two different walking conditions. We confirmed previous reports that peak hip extension and sagittal ROM is lower in THR patients compared to healthy controls(Beaulieu et al., 2010; Foucher et al., 2007), under both walking conditions. For joint moments and powers, the LF and NF groups functioned more poorly than controls, but the HF THR group matched or demonstrated higher magnitudes than control patients (Figures 1 and 2), a finding comparable to previous work (O'Connor et al., 2018). Conversely the effect of chronological age was less systematic during normal walking, and age-related differences were further reduced in fast walking.

\section{Stratification by age}

During normal walking, all THR age groups demonstrated compromised sagittal ROM and sagittal peak hip power generation compared to the healthy control group, consistent with previous reports (Beaulieu et al., 2010; Bennett et al., 2008; Colgan et al., 2016; Kolk et al., 2014; Varin et al., 2013),. In the current study, only the older two groups' (75-79 years and 80 years and above) hip kinematics and kinetic function (for the majority of variables), were significantly different to the healthy controls 
(Table 2). These findings are in contrast to previous studies which reported a uniformity between age strata, only identifying significant differences between all the different age strata combined, compared to a control group(Bennett et al., 2008; Bennett et al., 2017). In the present study, the younger patients (54-64 years old) produced more comparable gait outputs to control participants during normal walking (Table 2). Bayliss et al. (2017) found that revision rates in younger patients are higher than in older adults, even for the same post-operative duration. It is plausible to suggest that younger patients could potentially be at risk of increased revision rates due to the increased ROM, hip moments and joint contact forces(Li et al., 2015) associated with normal healthy gait (Table 2 and Figure 1).

It was anticipated that the inclusion of a fast walking condition might elicit greater differences between age groups due to the increase in demand(Lamontagne et al., 2011), however, the opposite was observed. Generally, overall differences between the oldest age groups compared to controls were reduced under the fast walking condition, suggesting that, when stratified by age, older patients were capable of performing at a higher level when required to (Table 3 and Supplementary File 2). This novel finding suggests that increasing age does not necessarily correlate with a decrease in the functional ceiling and further emphasises the importance of measuring patient function under more demanding activities. Furthermore, if the goal of THR is indeed to restore patient function across a range of activities(Learmonth et al., 2007), research outcome measures should focus on examining patients post-operatively using more demanding activities, which could provide a better indication of patients' return to function.

\section{Stratification by functional ability}

When patients were stratified by self-selected walking speed as a surrogate measure of functional ability, there were consistent and systematic differences between functional strata and healthy 
controls. The key findings were reductions in sagittal ROM, flexor moment, extensor moment (Figure 1), sagittal power generation and absorption between the LF group compared to HF and control group. The HF group were closely aligned functionally with the control group.

Previous studies have demonstrated that walking speed is a good surrogate indicator of overall function(Middleton et al., 2015; Studenski et al., 2011) and therefore it is reassuring that the HF patients, despite their hip replacement, are functionally aligned with the healthy controls. The greater magnitudes of joint moments and joint power (Figure 1 and 2), are well known to be associated with an increased walking speed(Browning and Kram, 2007; Schwartz et al., 2008). The results in the present study suggest that when THR patients were stratified by gait speed, consistent and clinically meaningful differences were more apparent between functional strata than was observed when the same dataset was stratified simply by age. Variables (i.e. frontal ROM, extension angle) that were systematically different when stratified by age (Tables 3 and 5 ) were still significant when stratified by function, with exception for medial GRF, which is of little clinical relevance. Stratification by gait speed, however, yielded further differentiation between groups in internal and external rotation moments, sagittal power absorption and generation and lateral GRF. As described above, when stratified by age, older adults were able to increase gait speed to a similar velocity and functional level (i.e. hip kinematics and kinetics), under the fast walking condition but when stratifying by function, the between-strata differences remained, indicating that the LF group remained relatively low functioning under fast walking conditions (Table 5 and 6 ).

This study does have a number of limitations. Firstly, gait speed was not used as a covariate in the analysis, and some of the between-group differences reported may be due to the direct influence of gait speed on kinematic and kinetic variables(Kirtley et al., 1985). Nevertheless the present dataset represents real-world activities in real-world THR cases and the effect of high or low functioning on local implant functioning or bearing surface wear is not normalized in the body to notional speeds or 
proportions of body weight. Secondly, surgical factors i.e. surgeon or surgical approach; were not controlled for in this study. Previous research has shown that surgical approach can differentially affect postoperative function in THR patients(Rathod et al., 2014). The control group were relatively well age matched overall, but not matched to individual corresponding age strata in the THR cohort, which would have allowed a more comprehensive analysis. Furthermore, only hip function was analysed in the present study and analysis of other joints would help to describe the overall function of patients and may highlight compensatory mechanisms used to cope with potential hip deficits. This study aimed however to understand how interpretation of hip function in particular varies depending on mode of stratification, and future analyses are required to explore the effects in other joints. The exploratory statistical analysis used in this instance was selected to highlight areas of interest for discussion and future studies rather than to infer a wider clinical significance. Through other timeseries-based approaches, such as statistical parametric mapping (Pataky, 2010) it would be possible to perform comparisons between groups across the full gait cycle and such approaches might be beneficial to future, hypothesis driven studies.

In conclusion, the present study demonstrates that stratifying patients by functionally relevant biomechanical factors such as gait speed, rather than patient age may be more robust in identifying clinically important functional differences. Patients who are low functioning at normal self-selected walking speed remain low functioning during more demanding conditions. Although there were some differences found in the age strata between older patients and younger patient groups, these were not as clear or consistent as when patients were stratified by gait speed, highlighting the potential benefits of stratifying by functional measures. This approach provides insight into the relative kinematics and kinetics of high function THR cases compared to normal and low function THR cases, in relation to healthy controls and in turn these findings could also provide a further insight into differences in revision rates across patient groups. Furthermore we have shown that measuring patients performing more demanding activities such as fast walking better differentiates functional 
compromises that are not necessarily obvious during normal walking. Other activities of daily living such as stair ascent/descent should also be considered in future as they may highlight further differences in function.

\section{Conflict of interest statement}

The authors have no competing interests to declare

\section{Appendices}

Supplementary files $1,2,3 \& 4$ can be found attached, and more information can be found at this

DOI: $\underline{\text { https://doi.org/10.5518/343 }}$

\section{Acknowledgements}

This study was supported by the European Union's Seventh Framework Programme (FP7/2007-2013) under grant agreement no. GA-310477 LifeLongJoints and by the Leeds Experimental Osteoarthritis Treatment Centre which is supported by Arthritis Research UK (grant no. 20083). This research is also supported by the National Institute for Health Research (NIHR) infrastructure at Leeds. The views expressed in this publication are those of the author(s) and not necessarily those of the NHS, the National Institute for Health Research or the Department of Health. The sponsors had no involvement in the study design, in the collection, analysis or interpretation of the data.

\section{References}


Alcock, L., Vanicek, N., O'Brien, T.D., 2013. Alterations in gait speed and age do not fully explain the changes in gait mechanics associated with healthy older women. Gait \& Posture 37, 586-592.

Bahl, J.S., Nelson, M.J., Taylor, M., Solomon, L.B., Arnold, J.B., Thewlis, D., Biomechanical changes and recovery of gait function after total hip arthroplasty for osteoarthritis: a systematic review and metaanalysis. Osteoarthritis and Cartilage.

Bahl, J.S., Nelson, M.J., Taylor, M., Solomon, L.B., Arnold, J.B., Thewlis, D., 2018. Biomechanical changes and recovery of gait function after total hip arthroplasty for osteoarthritis: a systematic review and meta-analysis. Osteoarthritis Cartilage 26, 847-863.

Bayliss, L.E., Culliford, D., Monk, A.P., Glyn-Jones, S., Prieto-Alhambra, D., Judge, A., Cooper, C., Carr, A.J., Arden, N.K., Beard, D.J., Price, A.J., 2017. The effect of patient age at intervention on risk of implant revision after total replacement of the hip or knee: a population-based cohort study. The Lancet 389, 1424-1430.

Beaulieu, M.L., Lamontagne, M., Beaulé, P.E., 2010. Lower limb biomechanics during gait do not return to normal following total hip arthroplasty. Gait \& Posture 32, 269-273.

Bell, A.L., Brand, R.A., Pedersen, D.R., 1987. Prediction of hip joint center location from external landmarks. Journal of biomechanics 20, 913-913.

Benedetti, M.G., Catani, F., Leardini, A., Pignotti, E., Giannini, S., 1998. Data management in gait analysis for clinical applications. Clinical Biomechanics 13, 204-215.

Bennett, D., Humphreys, L., O'Brien, S., Kelly, C., Orr, J.F., Beverland, D.E., 2008. Gait kinematics of age-stratified hip replacement patients--a large scale, long-term follow-up study. Gait Posture 28, 194 200.

Bennett, D., Ryan, P., O'Brien, S., Beverland, D.E., 2017. Gait kinetics of total hip replacement patientsA large scale, long-term follow-up study. Gait Posture 53, 173-178.

Bohannon, R.W., Williams Andrews, A., 2011. Normal walking speed: a descriptive meta-analysis. Physiotherapy 97, 182-189. 
Bolink, S.A.A.N., Lenguerrand, E., Brunton, L.R., Wylde, V., Gooberman-Hill, R., Heyligers, I.C., Blom, A.W., Grimm, B., 2016. Assessment of physical function following total hip arthroplasty: Inertial sensor based gait analysis is supplementary to patient-reported outcome measures. Clinical Biomechanics $32,171-179$.

Browning, R.C., Kram, R., 2007. Effects of obesity on the biomechanics of walking at different speeds. Medicine and science in sports and exercise 39, 1632-1641.

Cappozzo, A., Catani, F., Croce, U.D., Leardini, A., 1995. Position and orientation in space of bones during movement: anatomical frame definition and determination. Clinical biomechanics (Bristol, Avon) 10, 171-178.

Colgan, G., Walsh, M., Bennett, D., Rice, J., O’Brien, T., 2016. Gait analysis and hip extensor function early post total hip replacement. Journal of Orthopaedics 13, 171-176.

Ewen, A.M., Stewart, S., St Clair Gibson, A., Kashyap, S.N., Caplan, N., 2012. Post-operative gait analysis in total hip replacement patients-A review of current literature and meta-analysis. Gait \& Posture $36,1-6$.

Foucher, K.C., 2016. Identifying clinically meaningful benchmarks for gait improvement after total hip arthroplasty. Journal of orthopaedic research : official publication of the Orthopaedic Research Society 34, 88-96.

Foucher, K.C., Hurwitz, D.E., Wimmer, M.A., 2007. Preoperative gait adaptations persist one year after surgery in clinically well-functioning total hip replacement patients. Journal of biomechanics $40,3432-$ 3437.

Kirtley, C., Whittle, M.W., Jefferson, R.J., 1985. Influence of walking speed on gait parameters. Journal of Biomedical Engineering 7, 282-288.

Kolk, S., Minten, M.J., van Bon, G.E., Rijnen, W.H., Geurts, A.C., Verdonschot, N., Weerdesteyn, V., 2014. Gait and gait-related activities of daily living after total hip arthroplasty: A systematic review. Clinical Biomechanics. 
Lamontagne, M., Beaulieu, M.L., Beaulé, P.E., 2011. Comparison of joint mechanics of both lower limbs of tha patients with healthy participants during stair ascent and descent. Journal of Orthopaedic Research 29, 305-311.

Learmonth, I.D., Young, C., Rorabeck, C., 2007. The operation of the century: total hip replacement. Lancet (London, England) 370, 1508-1519.

Li, J., McWilliams, A.B., Jin, Z., Fisher, J., Stone, M.H., Redmond, A.C., Stewart, T.D., 2015. Unilateral total hip replacement patients with symptomatic leg length inequality have abnormal hip biomechanics during walking. Clinical Biomechanics 30, 513-519.

Middleton, A., Fritz, S.L., Lusardi, M., 2015. Walking speed: the functional vital sign. Journal of aging and physical activity $23,314-322$.

Nigg, B.M., Fisher, V., Ronsky, J.L., 1994. Gait characteristics as a function of age and gender. Gait \& Posture 2, 213-220.

O'Connor, J.D., Rutherford, M., Bennett, D., Hill, J.C., Beverland, D.E., Dunne, N.J., Lennon, A.B., 2018. Long-term hip loading in unilateral total hip replacement patients is no different between limbs or compared to healthy controls at similar walking speeds. Journal of biomechanics $80,8-15$.

Pataky, T.C., 2010. Generalized n-dimensional biomechanical field analysis using statistical parametric mapping. Journal of biomechanics 43, 1976-1982.

Perron, M., Malouin, F., Moffet, H., McFadyen, B.J., 2000. Three-dimensional gait analysis in women with a total hip arthroplasty. Clinical biomechanics (Bristol, Avon) 15, 504-515.

Rathod, P.A., Orishimo, K.F., Kremenic, I.J., Deshmukh, A.J., Rodriguez, J.A., 2014. Similar Improvement in Gait Parameters Following Direct Anterior \& Posterior Approach Total Hip Arthroplasty. The Journal of Arthroplasty 29, 1261-1264.

Schwartz, M.H., Rozumalski, A., Trost, J.P., 2008. The effect of walking speed on the gait of typically developing children. Journal of biomechanics 41, 1639-1650.

Studenski, S., Perera, S., Patel, K., et al., 2011. Gait speed and survival in older adults. JAMA 305, 5058. 
Towle, K.M., Monnot, A.D., 2016. An Assessment of Gender-Specific Risk of Implant Revision After Primary Total Hip Arthroplasty: A Systematic Review and Meta-analysis. The Journal of Arthroplasty $31,2941-2948$.

Varin, D., Lamontagne, M., Beaulé, P.E., 2013. Does the Anterior Approach for THA Provide Closer-ToNormal Lower-Limb Motion? The Journal of Arthroplasty 28, 1401-1407. 
Table 1. Patient demographics and walking speed $\left(\mathrm{ms}^{-1}\right)$ for each age strata. Values are reported as mean (SD) unless otherwise stated.

\begin{tabular}{llllllll}
\hline Group & $\begin{array}{l}\text { Age Stratum } \\
\text { (years) }\end{array}$ & $\begin{array}{l}\text { Number of } \\
\text { patients }\end{array}$ & Female:Male & $\begin{array}{l}\text { Age } \\
\text { (Years) }\end{array}$ & $\begin{array}{l}\text { BMI } \\
\left(\mathrm{kg} / \mathrm{m}^{2}\right)\end{array}$ & $\begin{array}{c}\text { Normal Walk } \\
\left(\mathrm{ms}^{-1}\right)\end{array}$ & $\begin{array}{c}\text { Fast Walk } \\
\left(\mathrm{ms}^{-1}\right)\end{array}$ \\
\hline 1 & 54 to 64 & 24 & $12: 12$ & $60.4(2.8)$ & $28.9(5.4)$ & $1.19(0.13)^{4,5}$ & $1.73(0.22)$ \\
2 & $65-69$ & 37 & $17: 20$ & $66.9(1.5)$ & $28.9(3.5)$ & $1.15(0.15)^{4,5}$ & $1.62(0.22)$ \\
3 & $70-74$ & 24 & $15: 9$ & $72.2(1.1)$ & $27.6(4.3)$ & $1.08(0.17)$ & $1.64(0.28)$ \\
4 & $75-79$ & 28 & $14: 14$ & $77.4(1.3)$ & $28.2(3.2)$ & $1.03(0.16)^{1,2, c}$ & $1.51(0.24)$ \\
5 & 80 and over & 24 & $12: 12$ & $82.3(3.1)$ & $26.7(3.2)$ & $1.02(0.18)^{1,2, c}$ & $1.57(0.24)$ \\
$\mathrm{c}$ & Healthy & 27 & $5: 22$ & $71.2(6.9)$ & $25.0(6.5)$ & $1.19(0.17)^{4,5}$ & $1.63(0.25)$ \\
& controls & & & & & & \\
\hline
\end{tabular}

$1,2,3,4,5, \mathrm{c}$ denotes significance $(p<0.05)$ with relevant group; ${ }^{\text {Tam }}$ denotes where Tamhane's test was used instead of Tukey's 
Table 2. Peak hip kinematic, moments, powers and GRF's in all three planes $(x, y, z)$ for all patient and healthy control groups, stratified by age during the normal walking condition.

\begin{tabular}{|c|c|c|c|c|c|c|c|c|c|c|c|c|c|}
\hline \multicolumn{14}{|c|}{ Kinematics $\left({ }^{\circ}\right)$} \\
\hline Group & Age Stratum & \multicolumn{2}{|c|}{ Peak Extension* } & \multicolumn{2}{|c|}{ Peak Flexion } & \multicolumn{2}{|c|}{ Sagittal ROM } & \multicolumn{2}{|c|}{ Peak Adduction } & \multicolumn{2}{|c|}{ Peak Abduction* } & \multicolumn{2}{|c|}{ Frontal ROM } \\
\hline 1 & 54 to 64 & -0.67 & (7.64) & 34.41 & (7.15) & $35.08^{c}$ & (4.18) & 9.07 & (3.41) & -0.72 & (4.27) & 9.79 & $(2.35)$ \\
\hline 2 & 65 to 69 & -1.00 & (7.19) & 34.12 & (6.52) & $35.12^{c}$ & $(6.04)$ & $7.92^{\mathrm{c}}$ & (2.94) & -1.30 & (3.13) & 9.21 & $(2.51)$ \\
\hline 3 & 70 to 74 & $2.21^{\mathrm{c}}$ & $(8.43)$ & 37.00 & (5.38) & $34.79^{c}$ & $(5.38)$ & 8.05 & (2.89) & -1.14 & (3.81) & 9.18 & $(2.50)$ \\
\hline 4 & 75 to 79 & $4.97^{\mathrm{c}}$ & (7.14) & 37.97 & (7.49) & $32.99^{c}$ & (3.63) & 8.89 & (3.52) & 0.88 & (3.43) & $8.01^{\mathrm{c}}$ & $(2.37)$ \\
\hline 5 & 80 and over & $0.24^{c}$ & (6.77) & 33.02 & $(6.82)$ & $32.78^{c}$ & (4.89) & 9.30 & (2.62) & -0.38 & (3.30) & 9.68 & $(2.92)$ \\
\hline c & Healthy controls & $-6.07^{3,4,5}$ & (6.43) & 34.84 & $(6.30)$ & $40.91^{1,2,3,4,5 \text { (Tam }}$ & $(4.83)$ & $10.30^{2}$ & (3.03) & -0.43 & (3.70) & $10.74^{4}$ & (3.06) \\
\hline & & \multicolumn{2}{|c|}{ Peak Internal Rotation } & \multicolumn{2}{|c|}{ Peak External Rotation } & \multicolumn{2}{|c|}{ Rotation ROM } & & & & & & \\
\hline 1 & 54 to 64 & 6.18 & $(5.88)$ & 4.35 & $(5.88)$ & 10.53 & (2.13) & & & & & & \\
\hline 2 & 65 to 69 & 2.93 & (5.94) & 7.93 & $(6.01)$ & 10.87 & (3.11) & & & & & & \\
\hline 3 & 70 to 74 & 2.69 & (8.48) & 8.52 & (9.38) & 11.22 & (3.39) & & & & & & \\
\hline 4 & 75 to 79 & 4.24 & (4.79) & 5.45 & (5.43) & 9.69 & $(2.71)$ & & & & & & \\
\hline 5 & 80 and over & 2.11 & (7.06) & 8.00 & (7.15) & 10.10 & (3.75) & & & & & & \\
\hline c & Healthy controls & 2.57 & $(6.06)$ & 7.64 & (6.58) & 10.21 & (2.14) & & & & & & \\
\hline \multicolumn{14}{|c|}{ GRF (BW) } \\
\hline & & \multicolumn{2}{|c|}{ Peak Vertical GRF } & \multicolumn{2}{|c|}{ Peak Medial GRF } & \multicolumn{2}{|c|}{ Peak Lateral GRF } & \multicolumn{2}{|c|}{ Peak Anterior GRF } & \multicolumn{2}{|c|}{ Peak Posterior GRF } & & \\
\hline 1 & 54 to 64 & $1.13^{4}$ & $(0.10)$ & $0.07^{3, c}$ & $(0.02)$ & 0.03 & $(0.02)$ & $0.19^{4,5}$ & $(0.03)$ & $0.16^{4,5}$ & $(0.03)$ & & \\
\hline 2 & 65 to 69 & 1.10 & $(0.07)$ & 0.07 & $(0.01)$ & 0.03 & $(0.02)$ & $0.17^{4,5}$ & $(0.03)$ & $0.14^{4}$ & $(0.04)$ & & \\
\hline 3 & 70 to 74 & 1.08 & $(0.06)$ & $0.06^{1}$ & $(0.02)$ & 0.03 & $(0.02)$ & 0.16 & $(0.04)$ & 0.14 & $(0.03)$ & & \\
\hline 4 & 75 to 79 & $1.06^{1, \mathrm{c}}$ & $(0.06)$ & 0.06 & $(0.01)$ & $0.02^{c}$ & $(0.02)$ & $0.14^{1,2, \mathrm{c}}$ & $(0.03)$ & $0.12^{1,2, c}$ & $(0.03)$ & & \\
\hline 5 & 80 and over & 1.09 & $(0.06)$ & 0.06 & $(0.01)$ & 0.03 & $(0.02)$ & $0.14^{1,2, c}$ & $(0.03)$ & $0.12^{1, c}$ & $(0.03)$ & & \\
\hline c & Healthy controls & $1.13^{4}$ & $(0.09)$ & $0.06^{1}$ & $(0.01)$ & $0.04^{4}$ & $(0.02)$ & $0.18^{4,5}$ & $(0.04)$ & $0.16^{4,5}$ & $(0.04)$ & & \\
\hline \multicolumn{14}{|c|}{ Moments (Nm/kg) } \\
\hline & & \multicolumn{2}{|c|}{ Peak Flexor Moment } & \multicolumn{2}{|c|}{ Peak Extensor Moment } & \multicolumn{2}{|c|}{ Peak Add Moment } & \multicolumn{2}{|c|}{ Peak Abd Moment } & \multicolumn{2}{|c|}{ Peak Int Rot Moment } & Pea & Rot Moment \\
\hline 1 & 54 to 64 & 0.84 & $(0.18)$ & 0.71 & $(0.21)$ & 0.12 & $(0.05)$ & $0.99^{4}$ & $(0.17)$ & 0.25 & $(0.09)$ & 0.03 & $(0.04)$ \\
\hline 2 & 65 to 69 & $0.83^{4}$ & $(0.22)$ & 0.68 & $(0.20)$ & 0.11 & $(0.06)$ & $0.89^{\mathrm{c}}$ & (0.11) & 0.22 & $(0.07)$ & 0.03 & $(0.04)$ \\
\hline 3 & 70 to 74 & 0.79 & (0.19) & 0.67 & $(0.21)$ & 0.13 & $(0.09)$ & 0.91 & (0.11) & 0.26 & (0.09) & 0.04 & $(0.02)$ \\
\hline 4 & 75 to 79 & $0.69^{2, c}$ & (0.19) & 0.65 & $(0.22)$ & 0.10 & $(0.05)$ & $0.88^{1, c}$ & $(0.10)$ & 0.26 & $(0.10)$ & $0.02^{\mathrm{c}}$ & $(0.02)$ \\
\hline 5 & 80 and over & 0.76 & $(0.16)$ & 0.61 & $(0.20)$ & 0.09 & $(0.06)$ & 0.92 & $(0.12)$ & 0.22 & (0.09) & $0.02^{\mathrm{c}}$ & $(0.02)$ \\
\hline c & Healthy controls & $0.83^{4}$ & $(0.08)$ & 0.71 & $(0.24)$ & 0.07 & $(0.06)$ & $0.95^{2,4}$ & $(0.20)$ & 0.24 & (0.11) & $0.05^{4,5}$ & $(0.04)$ \\
\hline & & & & & & Power (w & $\mathrm{s} / \mathrm{kg})$ & & & & & & \\
\hline & & Sagittal & lip Power & Sagit & k Hip Power & Frontal Pea & lip Power & Frontal P & Hip Power & Transv & Peak Hip Power & Transi & Peak Hip Power \\
\hline & & & & & ption & Gene & & & ption & & eration & & orption \\
\hline 1 & 54 to 64 & $1.09^{c}$ & $(0.39)$ & 0.54 & $(0.25)$ & $0.58^{4}$ & $(0.25)$ & $0.57^{4 \mathrm{Tam})}$ & $(0.30)$ & 0.05 & $(0.03)$ & 0.17 & $(0.11)$ \\
\hline 2 & 65 to 69 & $1.11^{\mathrm{c}}$ & $(0.39)$ & 0.59 & $(0.30)$ & 0.46 & $(0.17)$ & 0.38 & $(0.17)$ & 0.06 & $(0.06)$ & 0.14 & $(0.12)$ \\
\hline 3 & 70 to 74 & $1.01^{\mathrm{c}}$ & $(0.36)$ & 0.57 & $(0.27)$ & 0.44 & $(0.19)$ & 0.37 & $(0.15)$ & 0.06 & $(0.04)$ & 0.13 & $(0.07)$ \\
\hline 4 & 75 to 79 & $0.97^{\mathrm{c}}$ & $(0.41)$ & $0.44^{c}$ & $(0.25)$ & $0.39^{1}$ & $(0.16)$ & $0.35^{1(\mathrm{Tam})}$ & $(0.18)$ & 0.06 & $(0.05)$ & 0.13 & $(0.07)$ \\
\hline 5 & 80 and over & $0.91^{\mathrm{c}}$ & $(0.26)$ & $0.52^{c}$ & $(0.21)$ & 0.48 & $(0.15)$ & 0.37 & $(0.14)$ & 0.05 & $(0.04)$ & 0.12 & $(0.06)$ \\
\hline c & Healthy controls & $1.39^{1,2,3,4,4}$ & $(0.35)$ & $0.75^{4,5}$ & $(0.34)$ & 0.50 & $(0.25)$ & 0.52 & $(0.29)$ & 0.06 & $(0.03)$ & 0.17 & $(0.10)$ \\
\hline
\end{tabular}

and negative values indicate hip extension/abduction. 
Table 3. Peak hip kinematic, moments, powers and GRF's in all three planes $(x, y, z)$ for all patient and healthy control groups, stratified by age during the fast walking condition.

\begin{tabular}{|c|c|c|c|c|c|c|c|c|c|c|c|c|c|}
\hline \multicolumn{14}{|c|}{ Kinematics $\left({ }^{\circ}\right)$} \\
\hline Group & Age Stratum & \multicolumn{2}{|c|}{ Peak Extension* } & \multicolumn{2}{|c|}{ Peak Flexion } & \multicolumn{2}{|c|}{ Sagittal ROM } & \multicolumn{2}{|c|}{ Peak Adduction } & \multicolumn{2}{|c|}{ Peak Abduction* } & \multicolumn{2}{|c|}{ Frontal ROM } \\
\hline 1 & 54 to 64 & -3.70 & (8.78) & 38.01 & $(7.89)$ & 41.71 & $(5.76)$ & 10.28 & (3.73) & -1.40 & $(4.63)$ & 11.68 & $(2.80)$ \\
\hline 2 & 65 to 69 & -3.34 & (7.39) & 37.85 & $(6.85)$ & $41.19^{c}$ & $(7.29)$ & 8.89 & (3.09) & -1.86 & (3.18) & 10.74 & $(2.74)$ \\
\hline 3 & 70 to 74 & $-1.20^{c}$ & $(9.05)$ & 40.07 & $(6.24)$ & 41.27 & $(5.99)$ & 8.86 & (3.35) & -2.21 & $(4.67)$ & 11.07 & $(2.93)$ \\
\hline 4 & 75 to 79 & $0.84^{c}$ & $(5.90)$ & 39.06 & $(7.38)$ & $38.22^{\mathrm{c}}$ & $(5.99)$ & 8.71 & (3.48) & -0.52 & (2.67) & $9.24^{\mathrm{c}}$ & $(2.82)$ \\
\hline 5 & 80 and over & $-0.51^{c}$ & $(8.22)$ & 38.35 & $(7.36)$ & $38.87^{c}$ & $(5.55)$ & 9.58 & (2.82) & -2.07 & (3.02) & 11.66 & $(3.25)$ \\
\hline c & Healthy controls & $-8.06^{3,4,5}$ & $(7.32)$ & 37.94 & $(6.69)$ & 46.01 & $(6.08)$ & 11.20 & (3.09) & -1.07 & (3.99) & $12.27^{4}$ & $(3.58)$ \\
\hline \multicolumn{4}{|c|}{ Peak Internal Rotation } & \multicolumn{2}{|c|}{ Min External Rotation } & \multicolumn{2}{|c|}{ Rotation ROM } & & & & & & \\
\hline 1 & 54 to 64 & 6.53 & $(5.73)$ & -5.66 & $(6.74)$ & 12.19 & $(3.17)$ & & & & & & \\
\hline 2 & 65 to 69 & 3.27 & $(5.50)$ & -9.63 & $(5.93)$ & 12.90 & $(4.15)$ & & & & & & \\
\hline 3 & 70 to 74 & 2.81 & $(8.47)$ & -9.85 & $(7.88)$ & 12.66 & $(4.26)$ & & & & & & \\
\hline 4 & 75 to 79 & 3.38 & (4.49) & -7.85 & $(4.71)$ & 11.23 & (3.70) & & & & & & \\
\hline 5 & 80 and over & 2.71 & (6.54) & -10.12 & $(7.24)$ & 12.83 & $(5.36)$ & & & & & & \\
\hline c & Healthy controls & 1.46 & (6.58) & -8.68 & $(6.80)$ & 10.14 & $(2.62)$ & & & & & & \\
\hline \multicolumn{14}{|c|}{ GRF (BW) } \\
\hline & & \multicolumn{2}{|c|}{ Peak Vertical GRF } & \multicolumn{2}{|c|}{ Peak Medial GRF } & \multicolumn{2}{|c|}{ Peak Lateral GRF } & \multicolumn{2}{|c|}{ Peak Anterior GRF } & \multicolumn{2}{|c|}{ Peak Posterior GRF } & & \\
\hline 1 & 54 to 64 & 1.32 & $(0.13)$ & 0.08 & $(0.02)$ & 0.05 & $(0.02)$ & $0.24^{4,5}$ & $(0.04)$ & $0.23^{4,5}$ & $(0.04)$ & & \\
\hline 2 & 65 to 69 & 1.28 & $(0.13)$ & 0.07 & $(0.02)$ & $0.04^{c}$ & $(0.03)$ & $0.22^{4}$ & $(0.04)$ & $0.21^{4}$ & $(0.04)$ & & \\
\hline 3 & 70 to 74 & 1.26 & $(0.11)$ & 0.07 & $(0.02)$ & 0.05 & $(0.04)$ & 0.20 & $(0.05)$ & 0.20 & $(0.04)$ & & \\
\hline 4 & 75 to 79 & 1.20 & $(0.13)$ & 0.07 & $(0.02)$ & 0.04 & $(0.03)$ & $0.18^{1,2, \mathrm{c}}$ & $(0.05)$ & $0.17^{1,2, c}$ & $(0.05)$ & & \\
\hline 5 & 80 and over & 1.28 & $(0.16)$ & 0.07 & $(0.01)$ & 0.06 & $(0.03)$ & $0.19^{1}$ & $(0.03)$ & $0.19^{1}$ & $(0.05)$ & & \\
\hline c & Healthy controls & 1.30 & $(0.17)$ & 0.07 & $(0.02)$ & $0.06^{2}$ & $(0.03)$ & $0.22^{4}$ & $(0.05)$ & $0.22^{4}$ & $(0.05)$ & & \\
\hline \multicolumn{14}{|c|}{ Moments (Nm/kg) } \\
\hline & & \multicolumn{2}{|c|}{ Peak Flexor Moment } & \multicolumn{2}{|c|}{ Peak Extensor Moment } & \multicolumn{2}{|c|}{ Peak Add Moment } & \multicolumn{2}{|c|}{ Peak Abd Moment } & \multicolumn{2}{|c|}{ Peak Int Rot Moment } & \multicolumn{2}{|c|}{ Peak Ext Rot Moment } \\
\hline 1 & 54 to 64 & 1.25 & $(0.32)$ & 1.15 & $(0.25)$ & $0.21^{4, c(\mathrm{tam})}$ & $(0.06)$ & $1.17^{2,4}$ & $(0.22)$ & 0.35 & $(0.15)$ & 0.04 & $(0.04)$ \\
\hline 2 & 65 to 69 & 1.14 & $(0.27)$ & 1.04 & $(0.31)$ & 0.21 & $(0.13)$ & $1.02^{1}$ & $(0.16)$ & 0.31 & $(0.09)$ & 0.04 & $(0.06)$ \\
\hline 3 & 70 to 74 & 1.16 & $(0.27)$ & 1.14 & $(0.24)$ & 0.23 & $(0.17)$ & 1.06 & $(0.18)$ & 0.34 & $(0.12)$ & $0.08^{4,5}$ & $(0.09)$ \\
\hline 4 & 75 to 79 & 1.04 & $(0.21)$ & 1.10 & $(0.34)$ & $0.14^{1}$ & $(0.10)$ & $0.95^{1, c}$ & $(0.17)$ & 0.30 & $(0.14)$ & $0.03^{3}$ & $(0.04)$ \\
\hline 5 & 80 and over & 1.10 & $(0.20)$ & 1.12 & $(0.36)$ & 0.17 & $(0.12)$ & 1.07 & $(0.21)$ & 0.34 & $(0.16)$ & $0.01^{3}$ & $(0.03)$ \\
\hline c & Healthy controls & 1.20 & $(0.25)$ & 1.15 & $(0.25)$ & $0.14^{1}$ & $(0.08)$ & 1.16 & $(0.20)$ & 0.32 & $(0.12)$ & 0.06 & $(0.08)$ \\
\hline & & & & & & Power (w & & & & & & & \\
\hline & & Sagittal & $\begin{array}{l}\text { lip Power } \\
\text { ion }\end{array}$ & Sagit & $\begin{array}{l}\text { Hip Power } \\
\text { ption }\end{array}$ & Frontal & $\begin{array}{l}\text { lip Power } \\
\text { ion }\end{array}$ & Fronta & $\begin{array}{l}\text { Hip Power } \\
\text { ption }\end{array}$ & $\begin{array}{c}\text { Trans } \\
\text { Pow }\end{array}$ & $\begin{array}{l}\text { Peak Hip } \\
\text { neration }\end{array}$ & $\begin{array}{r}\text { Tran } \\
\text { Pov }\end{array}$ & $\begin{array}{l}\text { Peak Hip } \\
\text { sorption }\end{array}$ \\
\hline 1 & 54 to 64 & 2.21 & $(0.84)$ & 1.27 & $(0.67)$ & 0.66 & $(0.33)$ & $1.17^{4}$ & $(0.46)$ & 0.12 & $(0.06)$ & 0.27 & $(0.20)$ \\
\hline 2 & 65 to 69 & $1.86^{\mathrm{c}}$ & $(0.65)$ & 1.15 & $(0.50)$ & 0.54 & $(0.20)$ & 0.82 & $(0.39)$ & 0.13 & (0.11) & 0.24 & $(0.23)$ \\
\hline 3 & 70 to 74 & 2.03 & $(0.70)$ & 1.30 & $(0.48)$ & 0.53 & $(0.21)$ & 0.87 & $(0.37)$ & 0.12 & $(0.07)$ & 0.21 & $(0.12)$ \\
\hline 4 & 75 to 79 & 1.93 & $(0.74)$ & 1.04 & $(0.41)$ & 0.45 & $(0.19)$ & $0.72^{1}$ & $(0.57)$ & 0.10 & $(0.07)$ & 0.19 & $(0.13)$ \\
\hline 5 & 80 and over & $1.76^{c}$ & $(0.48)$ & 1.03 & $(0.38)$ & 0.55 & $(0.23)$ & 0.83 & $(0.38)$ & 0.11 & $(0.06)$ & 0.23 & $(0.16)$ \\
\hline c & Healthy controls & $2.41^{2,5}$ & $(0.63)$ & 1.38 & $(0.51)$ & 0.54 & $(0.23)$ & 1.03 & $(0.67)$ & 0.14 & $(0.08)$ & 0.23 & $(0.13)$ \\
\hline
\end{tabular}

$1,2,3,4,5, c$ denotes significance ( $p<0.05$ ) with relevant group; Tam denotes where Tamhane's test was used instead of Tukey's. *Positive values indicate hip flexion/adduction and negative values indicated hip extension/abduction. 
Table 4. Patient demographics and walking speed $\left(\mathrm{m} . \mathrm{s}^{-1}\right)$ for each function stratum. Values are reported as mean (SD) unless otherwise stated.

\begin{tabular}{|c|c|c|c|c|c|c|c|}
\hline Group & $\begin{array}{l}\text { Function } \\
\text { Stratum }\end{array}$ & $\begin{array}{c}\text { Number of } \\
\text { patients }\end{array}$ & Female:Male & Age (Years) & $\begin{array}{c}\mathrm{BMI} \\
\left(\mathrm{kg} / \mathrm{m}^{2}\right)\end{array}$ & $\begin{array}{c}\text { Normal Walk } \\
\left(\mathrm{m} \cdot \mathrm{s}^{-1}\right)\end{array}$ & $\begin{array}{c}\text { Fast Walk } \\
\left(\mathrm{m} \cdot \mathrm{s}^{-1}\right)\end{array}$ \\
\hline 1 & Low & 19 & $13: 6$ & $76.3(6.3)$ & $28.5(5.0)$ & $0.82(0.08)^{2,3, c}$ & $1.27(0.22)^{2,3, c}$ \\
\hline 2 & Normal & 99 & $50: 49$ & $71.2(7.8)$ & $28.3(3.9)$ & $1.10(0.09)^{1,3, c}$ & $1.60(0.19)^{1,3}$ \\
\hline 3 & High & 19 & $7: 12$ & $68.7(6.7)$ & $27.1(3.0)$ & $1.37(0.09)^{1,2, c}$ & $1.90(0.20)^{1,2, c}$ \\
\hline c & $\begin{array}{l}\text { Healthy } \\
\text { controls }\end{array}$ & 27 & $5: 22$ & $71.2(6.9)$ & $25(6.5)$ & $1.19(0.17)^{1,2,3}$ & $1.63(0.25)^{1,3}$ \\
\hline
\end{tabular}


Table 5. Peak hip kinematic, moments, powers and GRF's in all three planes $(x, y, z)$ for all patient and healthy control groups, stratified by gait speed during the normal walking condition.

\begin{tabular}{|c|c|c|c|c|c|c|c|c|c|c|c|c|c|}
\hline \multicolumn{14}{|c|}{ Kinematics $\left({ }^{\circ}\right)$} \\
\hline Group & Function Stratum & \multicolumn{2}{|c|}{ Peak Extension* } & \multicolumn{2}{|c|}{ Peak Flexion } & \multicolumn{2}{|c|}{ Sagittal ROM } & \multicolumn{2}{|c|}{ Peak Adduction } & \multicolumn{2}{|c|}{ Peak Abduction* } & \multicolumn{2}{|c|}{ Frontal ROM } \\
\hline 1 & Low & $1.75^{c}$ & $(7.75)$ & 32.78 & $(6.70)$ & $31.03^{2,3, c}$ & $(5.92)$ & 9.40 & (3.39) & 1.44 & (3.62) & $7.95^{c}$ & $(2.63)$ \\
\hline 2 & Normal & $1.26^{c}$ & (7.42) & 35.60 & $(6.86)$ & $34.34^{1, c}$ & $(4.48)$ & $8.52^{\mathrm{c}}$ & (3.14) & -0.79 & (3.63) & 9.31 & $(2.57)$ \\
\hline 3 & High & -0.67 & (8.88) & 36.04 & $(6.92)$ & $36.71^{1, \mathrm{c}}$ & (5.39) & 8.08 & $(2.56)$ & -1.39 & $(2.77)$ & 9.47 & $(2.28)$ \\
\hline \multirow[t]{2}{*}{ c } & Healthy controls & $-6.07^{1,2}$ & (6.43) & 34.84 & $(6.30)$ & $40.91^{1,2,3}$ & (4.83) & $10.30^{2}$ & (3.03) & -0.43 & (3.70) & $10.74^{1}$ & (3.06) \\
\hline & & \multicolumn{2}{|c|}{ Peak Internal Rotation } & \multicolumn{2}{|c|}{ Peak External Rotation } & \multicolumn{2}{|c|}{ Rotation ROM } & & & & & & \\
\hline 1 & Low & 3.10 & $(8.46)$ & 6.59 & $(9.02)$ & 9.69 & $(2.27)$ & & & & & & \\
\hline 2 & Normal & 3.86 & (6.44) & 6.48 & (6.71) & 10.35 & (3.11) & & & & & & \\
\hline 3 & High & 2.60 & (4.51) & 9.48 & $(4.79)$ & 12.08 & (3.15) & & & & & & \\
\hline c & Healthy controls & 2.57 & $(6.06)$ & 7.64 & $(6.58)$ & 10.21 & $(2.14)$ & & & & & & \\
\hline \multicolumn{14}{|c|}{ GRF (BW) } \\
\hline & & \multicolumn{2}{|c|}{ Peak Vertical GRF } & \multicolumn{2}{|c|}{ Peak Medial GRF } & \multicolumn{2}{|c|}{ Peak Lateral GRF } & \multicolumn{2}{|c|}{ Peak Anterior GRF } & \multicolumn{2}{|c|}{ Peak Posterior GRF } & & \\
\hline 1 & Low & $1.04^{2,3, c}$ & $(0.05)$ & 0.07 & $(0.01)$ & $0.02^{2,3, c}$ & $(0.02)$ & $0.11^{2,3, c}$ & $(0.02)$ & $0.10^{2,3, c}$ & $(0.03)$ & & \\
\hline 2 & Normal & $1.09^{1,3, c}$ & $(0.07)$ & 0.07 & $(0.01)$ & $0.03^{1,3, c}$ & $(0.02)$ & $0.16^{1,3, c}$ & $(0.03)$ & $0.14^{1,3, \mathrm{c}}$ & $(0.03)$ & & \\
\hline 3 & High & $1.17^{1,2}$ & (0.08) & 0.06 & $(0.01)$ & $0.04^{1,2}$ & $(0.02)$ & $0.20^{1,2}$ & $(0.03)$ & $0.17^{1,2}$ & (0.04) & & \\
\hline c & Healthy controls & $1.13^{1,2}$ & $(0.09)$ & 0.06 & $(0.01)$ & $0.04^{1,2}$ & $(0.02)$ & $0.18^{1,2}$ & $(0.04)$ & $0.16^{1,2}$ & $(0.04)$ & & \\
\hline \multicolumn{14}{|c|}{ Moments (Nm/kg) } \\
\hline & & \multicolumn{2}{|c|}{ Peak Flexor Moment } & Peak Es & or Moment & \multicolumn{2}{|c|}{ Peak Add Moment } & \multicolumn{2}{|c|}{ Peak Abd Moment } & \multicolumn{2}{|c|}{ Peak Int Rot Moment } & \multicolumn{2}{|c|}{ Peak Ext Rot Moment } \\
\hline 1 & Low & $0.60^{2,3, c}$ & $(0.16)$ & $0.51^{2,3, c}$ & $(0.17)$ & 0.09 & $(0.06)$ & $0.89^{3, c}$ & $(0.10)$ & $0.19^{2,3}$ & $(0.10)$ & $0.02^{c}$ & $(0.03)$ \\
\hline 2 & Normal & $0.77^{1,3}$ & (0.15) & $0.66^{1,3}$ & $(0.18)$ & 0.11 & $(0.06)$ & 0.91 & (0.13) & $0.24^{1}$ & (0.12) & $0.03^{c}$ & (0.03) \\
\hline 3 & High & $1.00^{1,2, c}$ & $(0.20)$ & $0.84^{1,2}$ & $(0.23)$ & 0.14 & $(0.06)$ & $0.97^{1}$ & (0.09) & $0.28^{1(\mathrm{Tam})}$ & $(0.14)$ & 0.04 & $(0.05)$ \\
\hline c & Healthy controls & $0.85^{1,3}$ & $(0.20)$ & $0.75^{1}$ & $(0.21)$ & 0.10 & $(0.06)$ & $0.99^{c(\mathrm{Tam})}$ & $(0.16)$ & 0.25 & $(0.11)$ & $0.05^{1,2}$ & $(0.05)$ \\
\hline \multicolumn{14}{|c|}{ Power (watts/kg) } \\
\hline & & \multicolumn{2}{|c|}{$\begin{array}{c}\text { Sagittal Peak Hip Power } \\
\text { Generation }\end{array}$} & \multicolumn{2}{|c|}{$\begin{array}{c}\text { Sagittal Peak Hip Power } \\
\text { Absorption }\end{array}$} & \multicolumn{2}{|c|}{$\begin{array}{c}\text { Frontal Peak Hip Power } \\
\text { Generation }\end{array}$} & \multicolumn{2}{|c|}{$\begin{array}{l}\text { Frontal Peak Hip } \\
\text { Power Absorption }\end{array}$} & $\begin{array}{l}\text { Transver } \\
\text { Power }\end{array}$ & $\begin{array}{l}\text { Peak Hip } \\
\text { neration }\end{array}$ & $\begin{array}{c}\text { Trans } \\
\text { Powc }\end{array}$ & $\begin{array}{l}\text { Peak Hip } \\
\text { sorption }\end{array}$ \\
\hline 1 & Low & $0.75^{2,3, c}$ & $(0.24)$ & $0.38^{3, c}$ & $(0.19)$ & $0.36^{3}$ & $(0.16)$ & $0.26^{2,3, c}$ & $(0.13)$ & 0.04 & $(0.02)$ & 0.11 & $(0.06)$ \\
\hline 2 & Normal & $0.99^{1,3, c}$ & $(0.30)$ & $0.52^{3, c}$ & $(0.25)$ & 0.47 & $(0.18)$ & $0.41^{1}$ & $(0.20)$ & 0.05 & $(0.04)$ & 0.14 & (0.09) \\
\hline 3 & High & $1.48^{1,2}$ & $(0.45)$ & $0.77^{1,2}$ & $(0.26)$ & $0.56^{1}$ & $(0.23)$ & $0.47^{1}$ & $(0.24)$ & 0.08 & $(0.07)$ & 0.16 & (0.10) \\
\hline c & Healthy controls & $1.39^{1,2}$ & $(0.35)$ & $0.75^{1,2}$ & $(0.34)$ & 0.50 & $(0.25)$ & $0.52^{1(\mathrm{Tam})}$ & $(0.29)$ & 0.06 & $(0.03)$ & 0.17 & $(0.10)$ \\
\hline
\end{tabular}

flexion/adduction and negative values indicate hip extension/abduction. 
Table 6. Peak hip kinematic, moments, powers and GRF's in all three planes $(x, y, z)$ for all patient and healthy control groups, stratified by gait speed during the fast walking condition.

\begin{tabular}{|c|c|c|c|c|c|c|c|c|c|c|c|c|c|}
\hline \multicolumn{14}{|c|}{ Kinematics $\left({ }^{\circ}\right)$} \\
\hline Group & Function Stratum & \multicolumn{2}{|c|}{ Peak Extension* } & \multicolumn{2}{|c|}{ Peak Flexion } & \multicolumn{2}{|c|}{ Sagittal ROM } & \multicolumn{2}{|c|}{ Peak Adduction } & \multicolumn{2}{|c|}{ Peak Abduction* } & \multicolumn{2}{|c|}{ Frontal ROM } \\
\hline 1 & Low & -1.73 & $(5.30)$ & 34.99 & $(4.72)$ & $36.72^{c}$ & $(8.11)$ & 8.77 & (3.14) & -0.44 & (3.41) & $9.21^{c}$ & (3.67) \\
\hline 2 & Normal & $-1.88^{c}$ & $(7.80)$ & 38.60 & (7.11) & $40.47^{c}$ & (5.95) & $9.30^{c}$ & (3.44) & -1.47 & (3.74) & 10.77 & $(2.77)$ \\
\hline 3 & High & -2.24 & (9.91) & 40.42 & (7.48) & 42.66 & (6.64) & 9.08 & (2.89) & -2.96 & (3.40) & 12.04 & (2.93) \\
\hline \multirow[t]{2}{*}{ c } & Healthy controls & $-8.06^{2}$ & $(7.32)$ & 37.94 & (6.69) & $46.01^{1,2}$ & (6.08) & $11.20^{2}$ & (3.21) & -1.07 & (3.99) & $12.27^{1}$ & (3.58) \\
\hline & & \multicolumn{2}{|c|}{ Peak Internal Rotation } & \multicolumn{2}{|c|}{ Peak External Rotation } & \multicolumn{2}{|c|}{ Rotation ROM } & & & & & & \\
\hline 1 & Low & 4.16 & (4.98) & 6.95 & (4.59) & 11.10 & $(2.93)$ & & & & & & \\
\hline 2 & Normal & 3.99 & (6.55) & 8.25 & $(6.85)$ & 12.24 & (3.95) & & & & & & \\
\hline 3 & High & 2.62 & $(5.08)$ & 11.29 & $(5.52)$ & $13.91^{c}$ & (4.87) & & & & & & \\
\hline c & Healthy controls & 1.46 & $(6.58)$ & 8.68 & $(6.80)$ & $10.14^{3}$ & $(2.62)$ & & & & & & \\
\hline \multicolumn{14}{|c|}{ GRF (BW) } \\
\hline & & \multicolumn{2}{|c|}{ Peak Vertical GRF } & \multicolumn{2}{|c|}{ Peak Medial GRF } & \multicolumn{2}{|c|}{ Peak Lateral GRF } & \multicolumn{2}{|c|}{ Peak Anterior GRF } & \multicolumn{2}{|c|}{ Peak Posterior GRF } & & \\
\hline 1 & Low & $1.13^{2,3, c}$ & $(0.09)$ & 0.07 & $(0.02)$ & $0.03^{c}$ & $(0.02)$ & $0.16^{2,3, c}$ & $(0.03)$ & $0.15^{2,3, c}$ & $(0.05)$ & & \\
\hline 2 & Normal & $1.27^{1}$ & $(0.13)$ & 0.07 & $(0.02)$ & 0.05 & $(0.03)$ & $0.21^{1}$ & $(0.04)$ & $0.21^{1}$ & $(0.04)$ & & \\
\hline 3 & High & $1.35^{1}$ & $(0.12)$ & 0.07 & $(0.02)$ & 0.06 & $(0.03)$ & $0.23^{1}$ & $(0.05)$ & $0.22^{1}$ & $(0.05)$ & & \\
\hline c & Healthy controls & $1.30^{1}$ & $(0.17)$ & 0.07 & $(0.02)$ & $0.06^{1}$ & $(0.03)$ & $0.22^{1}$ & $(0.05)$ & $0.22^{1}$ & $(0.05)$ & & \\
\hline \multicolumn{14}{|c|}{ Moments (Nm/kg) } \\
\hline & & \multicolumn{2}{|c|}{ Peak Flexor Moment } & \multicolumn{2}{|c|}{ Peak Extensor Moment } & \multicolumn{2}{|c|}{ Peak Add Moment } & \multicolumn{2}{|c|}{ Peak Abd Moment } & \multicolumn{2}{|c|}{ Peak Int Rot Moment } & \multicolumn{2}{|c|}{ Peak Ext Rot Moment } \\
\hline 1 & Low & $0.90^{2,3, c}$ & $(0.19)$ & 1.00 & $(0.20)$ & 0.15 & $(0.13)$ & $0.96^{c}$ & (0.19) & $0.21^{2,3}$ & $(0.08)$ & 0.03 & $(0.05)$ \\
\hline 2 & Normal & $1.13^{1,3}$ & $(0.24)$ & 1.09 & $(0.29)$ & 0.19 & $(0.12)$ & 1.06 & $(0.20)$ & $0.32^{1}$ & $(0.12)$ & 0.04 & $(0.06)$ \\
\hline 3 & High & $1.35^{1,2}$ & $(0.27)$ & 1.24 & $(0.37)$ & $0.24^{c}$ & $(0.13)$ & 1.08 & (0.15) & $0.37^{1}$ & (0.17) & 0.06 & (0.07) \\
\hline c & Healthy controls & $1.20^{1}$ & $(0.25)$ & 1.15 & $(0.25)$ & $0.14^{3}$ & $(0.08)$ & $1.16^{1}$ & $(0.20)$ & 0.31 & $(0.12)$ & 0.06 & $(0.08)$ \\
\hline \multicolumn{14}{|c|}{ Power (watts/kg) } \\
\hline & & \multicolumn{2}{|c|}{$\begin{array}{c}\text { Sagittal Peak Hip Power } \\
\text { Generation }\end{array}$} & \multicolumn{2}{|c|}{$\begin{array}{c}\text { Sagittal Peak Hip Power } \\
\text { Absorption }\end{array}$} & \multicolumn{2}{|c|}{$\begin{array}{c}\text { Frontal Peak Hip Power } \\
\text { Generation }\end{array}$} & $\begin{array}{l}\text { Front } \\
\text { Power }\end{array}$ & $\begin{array}{l}\text { eak Hip } \\
\text { sorption }\end{array}$ & $\begin{array}{r}\text { Transve } \\
\text { Power }\end{array}$ & $\begin{array}{l}\text { Peak Hip } \\
\text { neration }\end{array}$ & $\begin{array}{l}\text { Transve } \\
\text { Power }\end{array}$ & $\begin{array}{l}\text { eak Hip } \\
\text { rption }\end{array}$ \\
\hline 1 & Low & $1.50^{3, \mathrm{c}}$ & $(0.48)$ & $0.78^{3, c}$ & $(0.38)$ & 0.45 & $(0.25)$ & 0.62 & $(0.37)$ & $0.07^{3}$ & $(0.04)$ & 0.16 & $(0.09)$ \\
\hline 2 & Normal & $1.86^{3, c}$ & $(0.60)$ & $1.12^{3}$ & $(0.48)$ & 0.54 & $(0.24)$ & 0.89 & $(0.45)$ & 0.12 & $(0.08)$ & 0.24 & $(0.18)$ \\
\hline 3 & High & $2.70^{1,2}$ & $(0.80)$ & $1.58^{1,2}$ & $(0.46)$ & 0.63 & $(0.19)$ & 0.99 & $(0.47)$ & $0.15^{1}$ & $(0.11)$ & 0.23 & $(0.21)$ \\
\hline c & Healthy controls & $2.41^{1,2}$ & $(0.63)$ & $1.38^{1}$ & $(0.51)$ & 0.54 & $(0.23)$ & 1.03 & (0.67) & 0.14 & $(0.08)$ & 0.23 & $(0.13)$ \\
\hline
\end{tabular}

flexion/adduction and negative values indicate hip extension/abduction. 